\title{
Prediction of early postoperative desaturation in extreme older patients after spinal anesthesia for femur fracture surgery: a retrospective analysis
}

\author{
Youn Yi Jo ${ }^{1 \star}$, Chun Gon Park ${ }^{2 \star}$, Ji Yeon Lee ${ }^{1}$, Sun Koo Kwon ${ }^{1}$, and \\ Hyun Jeong Kwak ${ }^{1}$ \\ Department of Anesthesiology and Pain Medicine, ${ }^{1}$ Gil Medical Center, Gachon University College of Medicine, \\ Incheon, ${ }^{2}$ Severance Hospital, Yonsei University College of Medicine, Seoul, Korea
}

\begin{abstract}
Background: Postoperative desaturation in older individuals is rarely addressed in the literature. The objective of this retrospective study was to investigate whether a preoperative spirometric test and arterial blood gas analysis (ABGA) might predict postoperative desaturation after spinal anesthesia in extreme older patients.

Methods: The medical records of 399 patients (age $\geq 80$ yrs) who were administered spinal anesthesia for a femur neck fracture surgery were retrospectively reviewed. Early postoperative desaturation was defined as a reduction of oxygen saturation $\left(\mathrm{SpO}_{2}\right)$ below $90 \%$ within 3 days of surgery, despite $\mathrm{O}_{2}$ supply via a nasal prong. Binary logistic regression analysis was used to identify predictors of early postoperative desaturation.

Results: The incidence of postoperative desaturation was $12.5 \%$. Major morbidity rate was significantly higher in the desaturation group $(\mathrm{n}=50)$ than that in the non-desaturation group $(\mathrm{n}=349)(14 \%$ vs. $3.2 \%, P=0.001)$ with more frequent postoperative stays in the intensive care unit $(22 \% \mathrm{vs.} 12 \%, \mathrm{P}=0.004)$. In a binary logistic regression analysis, preoperative ratio of arterial oxygen partial pressure to fractional inspired oxygen $\left(\mathrm{PaO}_{2} / \mathrm{FiO}_{2}\right.$ ratio $)(\mathrm{OR}, 0.972 ; 95 \% \mathrm{CI}$ $0.952-0.993 ; \mathrm{P}=0.010)$ and history of cardiovascular disease (OR, 2.127; 95\% CI 1.004-4.507; $\mathrm{P}=0.049)$ predicted postoperative desaturation.

Conclusions: Preoperative $\mathrm{PaO}_{2} / \mathrm{FiO}_{2}$ ratio, but not preoperative spirometry, was predictive of the postoperative desaturation in older patients after being administered spinal anesthesia for femur fracture surgery. Based on our results, preoperative ABGA may be helpful in predicting early postoperative desaturation in these patients.
\end{abstract}

Keywords: Arterial blood gas analysis; Femur neck fracture; Frail older individuals; Postoperative hypoxia; Spinal anesthesia; Spirometry.

Corresponding author: Hyun Jeong Kwak, M.D., Ph.D.

Department of Anesthesiology and Pain Medicine, Gil Medical Center, Gachon University College of Medicine, 21 Namdong-daero 774beon-gil, Namdong-gu, Incheon 21565, Korea

Tel: +82-32-460-3400, Fax: +82-32-469-6319, Email: hyun615@gilhospital.com

ORCID: https://orcid.org/0000-0003-4432-8510

${ }^{*}$ Co-first author: Youn Yi Jo and Chun Gon Park equally contributed.

Received: May 19, 2019. Revised: July 2, 2019 (1st); July 22, 2019 (2nd). Accepted: August 1, 2019.

Korean J Anesthesiol 2019 December 72(6): 599-605

https://doi.org/10.4097/kja.19220

(c) This is an open-access article distributed under the terms of the Creative Commons Attribution Non-Commercial License (http://creativecommons.org/ licenses/by-nc/4.0/), which permits unrestricted non-commercial use, distribution, and reproduction in any medium, provided the original work is properly cited. 


\section{Introduction}

Given rapid increases in older populations, frailty has become a medical issue of concern. Frailty is strongly associated with respiratory impairment and may substantially increase mortality [1]. In an analysis of the relationship between respiratory impairment (as determined by spirometry) and frailty, it was found that individuals aged 65 to 80 years with respiratory impairment were more likely to exhibit frailty and that older individuals with respiratory impairment and frailty had an elevated mortality rate [1]. Forced expiratory volume in 1 second $\left(\mathrm{FEV}_{1}\right)$ declines significantly during aging; this decline accelerates after 70 years of age and can lead to inadequate ventilation [2]. In individuals aged over 65, pulmonary function decline is independently associated with hospital admission and death [2]. Another cohort study analyzed the usefulness of forced vital capacity (FVC), $\mathrm{FEV}_{1}$, and $\mathrm{FEV}_{1} / \mathrm{FVC}$ ratio data obtained by spirometry as well as respiratory symptoms as diagnostic tools for chronic obstructive pulmonary disease (COPD) and restrictive pulmonary disease [3] and concluded that severe and moderate COPD and restrictive lung disease were significantly associated with a higher risk of death [3]. Preoperative arterial blood gas analysis (ABGA) is not recommended as a routine preoperative evaluation, but due to the high incidence of pulmonary complications in older individuals with hip fractures, some clinicians recommend preoperative $\mathrm{ABGA}$ as a routine preoperative workup in these patients [4].

Femur fractures are closely associated with frailty, also defined as a state of increased vulnerability due to age-related declines in physiological reserves [5]. In a clinical report, up to $72 \%$ of femur neck fracture patients were found to have postoperative hypoxia 1 day after surgery [6]. Although a recent analysis of data on 7,585 individuals (median age 80 years) reported that the mortality rates after general and regional anesthesia in older patients with hip fracture were similar [7-9], spinal anesthesia might be preferred in those at risk of postoperative respiratory impairment, as recovery of lung volume is probably greater after spinal anesthesia [10].

Despite the importance of post-anesthetic care in older individuals who represent a high health care burden, little information is available in the literature regarding the prediction of postoperative hypoxia after administering spinal anesthesia for femur fracture surgery in older patients. We hypothesized that a preoperative spirometric test and ABGA results might predict postoperative desaturation in extreme older individuals $(\geq 80$ years old) after spinal anesthesia administration for femur neck fracture surgery.

\section{Materials and Methods}

After obtaining approval from the ethics committee of our institute (GBIRB 2017-059), we reviewed the archived medical records of 534 patients treated at our hospital (a 1400-bed tertiary referral hospital) from January 2007 to November 2017. The keywords used for searching were "femur neck fracture" or "intertrochanter fracture" and an age of $\geq 80$ years. Of the 534 records initially identified, 135 were excluded from the analysis (general anesthesia, 54 records; no spirometric results, 67; medical record loss, 14). Accordingly, the records of 399 patients were analyzed (349 of non-desaturation group and 50 of desaturation group). In accordance with our institute's surgical evaluation protocol, all enrolled patients underwent a spirometric test and ABGA preoperatively. However, if patients were unable to undergo these tests due to their medical condition (such as unconsciousness, tracheostomy, or bed-ridden state), the patients were excluded from the analysis.

Spirometric testing included $\mathrm{FVC}, \mathrm{FEV}_{1}$, and $\mathrm{FEV}_{1} / \mathrm{FVC}$ ratio, and $\mathrm{ABGA}$ included arterial oxygen $\left(\mathrm{PaO}_{2}\right), \mathrm{PaO}_{2} / \mathrm{FiO}_{2}$ ratio, carbon dioxide tension $\left(\mathrm{PaCO}_{2}\right)$, base deficit and lactate. Demographic data included preoperative histories that were categorized as cardiovascular, pulmonary, and central nervous system (CNS) diseases. Cardiovascular diseases included angina pectoris, myocardial infarction, congestive heart failure, valvular heart disease, atrial fibrillation, and high degree atrioventricular block. Pulmonary diseases included COPD, asthma, recent pneumonia, and advanced lung cancer. CNS diseases included cerebrovascular attack, Parkinson's disease, intracranial hemorrhage, and advanced dementia. Perioperative data included preor post-operative hypoxia, delirium, and major complications, such as hospital-acquired pneumonia, pulmonary embolism, cerebrovascular attack, uncompensated cardiac events, and mortality within three months after surgery. Other major morbidities were defined as life threatening conditions with or without major complications excluding mortality.

Spinal anesthesia was administered to patients in the lateral decubitus position using $0.5 \%$ heavy bupivacaine by anesthesiologists. Target sensory block levels were under the 6th thoracic segment (T6). During the spinal anesthesia administration, hemodynamic data and oxygen saturation $\left(\mathrm{SpO}_{2}\right.$ determined by pulse oximetry) were monitored. Most extreme older patients were not sedated during spinal anesthesia. However, if necessary, low doses of midazolam or dexmedetomidine were used according to the patient's medical condition.

Patients were discharged from our post-anesthetic care unit when mean arterial pressure and heart rate were maintained within $\pm 20 \%$ of baseline values, $\mathrm{SpO}_{2}$ was $\geq 95 \%$ with or without administration of $\mathrm{O}_{2}$ at $1-3 \mathrm{~L} / \mathrm{min}$ via a nasal prong, and sensory block level was $<$ T10. Perioperative transfusion of 
packed red blood cells was performed considering the hemodynamic parameters and hematocrit (target $30 \%$ ). Early postoperative desaturation was defined as a $\mathrm{SpO}_{2}$ of $<90 \%$ despite $\mathrm{O}_{2}$ via a nasal prong within 3 days of surgery [11]. Hypotension was defined as a mean arterial pressure of $<80 \%$ of baseline and a systolic blood pressure of $<90 \mathrm{mmHg}$.

Patients were recommended $\mathrm{O}_{2}$ at $1-3 \mathrm{~L} / \mathrm{min}$ via a nasal prong as appropriate immediately postoperatively and $\mathrm{SpO}_{2}$ was monitored bedside for all. On the day of surgery, the caregiver was trained to notify the nurse when $\mathrm{SpO}_{2}$ was low $(<90 \%)$. When a desaturation event occurred, the nurses checked the patient and then notified the doctor. From 1-day postoperatively, $\mathrm{SpO}_{2}$ was only monitored in bed-ridden patients during sleep and/or in patients who required a persistent oxygen supply according to previous $\mathrm{SpO}_{2}$ or results of ABGA. Postoperative pain was controlled by intravenous injection of tramadol 100 $\mathrm{mg}$ or diclofenac $75 \mathrm{mg}$, when the pain score was over 5 using an 11-point numeric rating score $(0-10)$.

Data were analyzed using SPSS ver. 17 (SPSS, Inc., USA). Values are presented as mean $\pm \mathrm{SD}$, median (interquartile range), or as numbers of patients (\%). To evaluate the significance of differences between the desaturation and non-desaturation groups, we used an independent $t$-test for continuous variables

Table 1. Patient Characteristics and Perioperative Transfusion

\begin{tabular}{lccc}
\hline & $\begin{array}{c}\text { Desaturation } \\
(\mathrm{n}=50)\end{array}$ & $\begin{array}{c}\text { Non- } \\
\text { desaturation } \\
(\mathrm{n}=349)\end{array}$ & $\begin{array}{c}\mathrm{P} \\
\text { value }\end{array}$ \\
\hline Age $(\mathrm{yr})$ & $84.9 \pm 4.3$ & $84.9 \pm 5.9$ & 0.940 \\
Gender $(\mathrm{M} / \mathrm{F})$ & $7 / 43$ & $70 / 279$ & 0.551 \\
Weight $(\mathrm{kg})$ & $52.1 \pm 11.9$ & $52.6 \pm 10.0$ & 0.789 \\
Height $(\mathrm{cm})$ & $153.4 \pm 6.2$ & $155.3 \pm 7.9$ & 0.119 \\
Body mass index $\left(\mathrm{kg} / \mathrm{m}^{2}\right)$ & $22.1 \pm 4.7$ & $21.7 \pm 3.7$ & 0.507 \\
ASA $\geq 3$ & $29(58)$ & $166(48)$ & 0.167 \\
Blocked level (thoracic segment) & $6.0(6.0-7.8)$ & $6.0(5.3-8.0)$ & 0.193 \\
Preoperative laboratory tests & & & \\
$\quad$ Low albumin $(<3.5$ g/dl) & $14(28)$ & $122(35)$ & 0.332 \\
Abnormal BUN & $20(40)$ & $165(47)$ & 0.334 \\
$\quad$ Hemoglobin $(\mathrm{g} / \mathrm{dl})$ & $11.1 \pm 1.8$ & $11.2 \pm 1.7$ & 0.712 \\
Medical histories & & & \\
$\quad$ Cardiac diseases & $12(24)$ & $53(15)$ & 0.114 \\
Pulmonary diseases & $2(4)$ & $36(10)$ & 0.155 \\
CNS diseases & $17(34)$ & $96(28)$ & 0.341 \\
Intra-operative sedation & $14(28)$ & $82(23)$ & 0.923 \\
$\quad$ Midazolam/dexmedetomidine & $3 / 11$ & $22 / 60$ & \\
Postoperative PCA & $49(98)$ & $337(97)$ & 0.983 \\
Perioperative RBC transfusion & $43(86)$ & $267(77)$ & 0.131 \\
\hline
\end{tabular}

Values are presented as means $\pm \mathrm{SD}$, medians (interquartile range), or number of patients (\%). ASA: American Society of Anesthesiologists, CNS: central nervous system. Low albumin: preoperative albumin level $<3.5 \mathrm{~g} / \mathrm{dl}$; Abnormal BUN: preoperative BUN level of $<8$ or $>21 \mathrm{mg} / \mathrm{dl}$, RBC: packed red blood cell, Postoperative PCA: postoperative opioidbased patient-controlled analgesia. and a chi-square test as a non-parametric test. Binary logistic regression analysis was used to identify predictors of early postoperative desaturation. Receiver operating characteristic (ROC) curves were analyzed to determine whether any factor that was found to be statistically significant by binary logistic regression analysis could predict postoperative desaturation. Optimal cutoff value for predicting postoperative desaturation was determined using Youden index. Statistical significance was accepted for $\mathrm{P}$ values $<0.05$. Propensity score matched cohort balanced on age, gender, previous morbidity except pulmonary disease, and laboratory values were analyzed to predict the effect of preoperative spirometric test on postoperative desaturation.

\section{Results}

Patient characteristics and perioperative transfusion requirements are presented in Table 1. The overall incidence of postoperative desaturation was $12.5 \%$ (50 of 399 patients). Mean age was 84.9 years in both non-desaturation groups and the desaturation and American Society of Anesthesiologists (ASA) physical statuses and previous histories of pulmonary diseases were similar in the two study groups.

Preoperative spirometric and ABGA results are detailed in Table 2. Preoperative $\mathrm{PaO}_{2} / \mathrm{FiO}_{2}$ ratio was significantly lower in the desaturation group than in the non-desaturation group (395 \pm 79 vs. $366 \pm 66, \mathrm{P}=0.006)$.

Postoperative courses are presented in Table 3. Overall 3-month mortality was $3.8 \%$ (15 of the 399 patients), and no intergroup difference was observed between the desaturation and non-desaturation groups (8\% [4 of 50 patients] and 3\% [11

Table 2. Preoperative Spirometric Test and Arterial Blood Gas Analysis

\begin{tabular}{lccc}
\hline & $\begin{array}{c}\text { Desaturation } \\
(\mathrm{n}=50)\end{array}$ & $\begin{array}{c}\text { Non- } \\
\text { desaturation } \\
(\mathrm{n}=349)\end{array}$ & P value \\
\hline Spirometry & $1.15 \pm 0.44$ & $1.21 \pm 0.44$ & 0.396 \\
$\mathrm{FEV}_{1}(\mathrm{~L})$ & $68.3 \pm 23.1$ & $74.5 \pm 27.5$ & 0.135 \\
$\mathrm{FEV}_{1}(\%)$ & $1.56 \pm 0.53$ & $1.67 \pm 0.58$ & 0.214 \\
$\mathrm{FVC} \mathrm{(L)}$ & $60.8 \pm 17.4$ & $65.8 \pm 20.8$ & 0.214 \\
$\mathrm{FVC}(\%)$ & $72.2 \pm 11.2$ & $72.2 \pm 10.6$ & 0.977 \\
$\mathrm{FEV}_{1} / \mathrm{FVC} \mathrm{ratio}(\%)$ & & & \\
$\mathrm{Arterial} \mathrm{blood} \mathrm{gas} \mathrm{analysis}$ & $7.45 \pm 0.04$ & $7.45 \pm 0.04$ & 0.970 \\
$\mathrm{pH}$ & $77.8 \pm 23.8$ & $81.2 \pm 22.4$ & 0.314 \\
$\mathrm{PaO}_{2}(\mathrm{mmHg})$ & $366 \pm 66$ & $395 \pm 79$ & 0.006 \\
$\mathrm{PaO}_{2} / \mathrm{FiO}$ ratio & $32.1 \pm 6.6$ & $32.4 \pm 5.7$ & 0.738 \\
$\mathrm{PaCO}_{2}(\mathrm{mmHg})$ & $-0.4 \pm 2.9$ & $-0.8 \pm 3.6$ & 0.557 \\
$\mathrm{Base} \mathrm{deficit}(\mathrm{mmol} / \mathrm{L})_{\mathrm{Lactate}(\mathrm{mmol} / \mathrm{L})}^{1.0 \pm 0.5}$ & $0.0 \pm 0.6$ & 0.931 \\
\hline
\end{tabular}

Values are presented as mean $\pm \mathrm{SD}$. $\mathrm{FEV}_{1}$ : forced expiratory volume in 1 second, FVC: forced vital capacity, $\mathrm{PaO}_{2} / \mathrm{FiO}_{2}$ ratio: the ratio of arterial oxygen partial pressure to fractional inspired oxygen. 
of 349 patients], respectively, $\mathrm{P}=0.092$ ). Fifteen patients died within three months of surgery due to the following reasons: sudden cardiac arrest $(n=3)$, septic shock $(n=10$; 9 from pneumonia and 1 from a urinary tract infection), acute kidney injury $(\mathrm{n}=1)$, and previous malignancy $(\mathrm{n}=1)$. The causes of major morbidities (excluding death) were pneumonia, pulmonary thromboembolism, and upper gastrointestinal bleeding, and all of these morbidities occurred in the desaturation group. Overall major morbidity (including death) rates in the desaturation and non-desaturation groups were $14 \%$ (7 of 50 patients) and $3.2 \%$ (11 of 349 patients), respectively $(\mathrm{P}=0.001)$. Hypotension was the most frequent postoperative complication in the desaturation and non-desaturation groups (46\% [ 23 of 50 patients] and $45 \%$ [ 157 of 349 patients], respectively; $\mathrm{P}=0.906$ ). The occurrence of delirium was significantly higher in the desaturation group (40\% [ 20 of 50 patients] vs. $26 \%$ [91 of 349 patients], $\mathrm{P}$ $=0.04$ ), and postoperative ICU admission was more frequent in the desaturation group (22\% [11 of 50 patients] vs. $12 \%$ [41 of 349 patients], $\mathrm{P}=0.004$ ). However, median durations [interquartile range] of ICU stay were similar in the desaturation and non-desaturation groups (5.5 [3-10.5] and 4 [2-7]; $\mathrm{P}=0.762$ ).

Regression analysis results for the prediction of postoperative

Table 3. Postoperative Morbidities and Mortalities in the Two Study Groups

\begin{tabular}{lccr}
\hline & $\begin{array}{c}\text { Desaturation } \\
(\mathrm{n}=50)\end{array}$ & $\begin{array}{c}\text { Non- } \\
\text { desaturation } \\
(\mathrm{n}=349)\end{array}$ & P value \\
\hline $\begin{array}{l}\text { Postoperative 3-month } \\
\text { mortality }\end{array}$ & $4(8)$ & $11(3)$ & 0.092 \\
$\begin{array}{l}\text { Delirium } \\
\text { Hypotension }\end{array}$ & $20(40)$ & $91(26)$ & 0.040 \\
$\begin{array}{l}\text { Other major morbidities } \\
\text { Postoperative ICU admission }\end{array}$ & $23(46)$ & $157(45)$ & 0.906 \\
$\begin{array}{l}\text { Length of ICU stay (days) } \\
\text { (1) }\end{array}$ & $5.5(3.0-10.5)$ & $4.0(2.0)$ & $<0.001$ \\
& & $41(12)$ & 0.004 \\
\end{tabular}

Values are presented as numbers of patients (\%) or median (interquartile range). ICU: intensive care unit. Other major morbidities included pneumonia, pulmonary thromboembolism, and upper gastrointestinal bleeding. desaturation are presented in Table 4. Of the variables listed in Tables 1 and 2, peri-operative transfusions of RBCs, $\mathrm{FEV}_{1}$ (\%), FVC (\%), preoperative $\mathrm{PaO}_{2} / \mathrm{FiO}_{2}$ ratio, and histories of cardiovascular and pulmonary diseases were found to differ in the two study groups with $\mathrm{P}$ values of $<0.2$ by univariate regression analysis. In the multivariate regression analysis, $\mathrm{PaO}_{2} / \mathrm{FiO}_{2}$ ratio (OR, 0.972; 95\% CI 0.952-0.993; $\mathrm{P}=0.010$ ) and histories of cardiovascular disease (OR, 2.127; 95\% CI 1.004-4.507; P = 0.049 ) predicted postoperative desaturation after femur neck surgery under spinal anesthesia (Nagelkerke $r^{2}=0.08$ ). The ROC curve of $\mathrm{PaO}_{2} / \mathrm{FiO}_{2}$ ratio revealed that the area under the curve for predicting postoperative desaturation was 0.602 (95\% CI $0.519-0.684, \mathrm{P}=0.020)$ and the optimal cut-off value was 351 (sensitivity, 63.3\%; specificity, 60.0\%).

\section{Discussion}

The incidence of early postoperative desaturation was $12.5 \%$ in older patients (aged $\geq 80$ years) after femur neck surgery under spinal anesthesia in this retrospective study. Preoperative $\mathrm{PaO}_{2} / \mathrm{FiO}_{2}$ ratio, but not preoperative $\mathrm{FVC}$ and $\mathrm{FEV}_{1}$ value of spirometry, was predictive of postoperative desaturation after femur neck surgery under spinal anesthesia. The incidences of major morbidities and delirium were higher in patients who experienced postoperative desaturation events. To the best of our knowledge, the present study represents the first attempt to determine the relationship between preoperative pulmonary function and postoperative desaturation in extreme older individuals.

Spirometry provides valuable information on the dynamics of pulmonary function. $\mathrm{FEV}_{1}$ decline starts at age 30-40 years at a rate of $25-30 \mathrm{ml} /$ year, but after age 70 this rate of decline doubles to $60 \mathrm{ml} /$ year [4]. Some controversy exists regarding the ability of preoperative spirometry to predict postoperative pulmonary complications. In an earlier analysis, patients with an abnormal $\mathrm{FEV}_{1}$ were observed to have higher pulmonary complication rates after vascular surgery [12], and in another analysis, six-fold increases in non-respiratory complications,

Table 4. Regression Analysis for Predicting Postoperative Desaturation

\begin{tabular}{|c|c|c|c|c|c|c|}
\hline \multirow{2}{*}{ Variables } & \multicolumn{3}{|c|}{ Univariate analysis } & \multicolumn{3}{|c|}{ Multivariate analysis } \\
\hline & OR & $95 \% \mathrm{CI}$ & $P$ value & OR & $95 \%$ CI & $P$ value \\
\hline Perioperative transfusion & 1.887 & $0.817-4.354$ & 0.137 & 1.910 & $0.813-4.486$ & 0.137 \\
\hline $\mathrm{PaO}_{2} / \mathrm{FiO}_{2}$ ratio & 0.974 & $0.954-0.995$ & 0.015 & 0.972 & $0.952-0.993$ & 0.010 \\
\hline $\mathrm{FEV}_{1}(\%)$ & 0.991 & $0.979-1.003$ & 0.135 & 1.000 & $0.971-1.029$ & 0.979 \\
\hline FVC (\%) & 0.987 & $0.972-1.003$ & 0.108 & 0.989 & $0.952-1.027$ & 0.568 \\
\hline Cardiac diseases & 1.764 & $0.866-3.594$ & 0.118 & 2.127 & $1.004-4.507$ & 0.049 \\
\hline Pulmonary diseases & 0.362 & $0.084-1.554$ & 0.172 & 0.303 & $0.067-1.372$ & 0.121 \\
\hline
\end{tabular}

OR: odds ratio, $95 \% \mathrm{CI}$ : $95 \%$ confidence interval, $\mathrm{PaO}_{2} / \mathrm{FiO}_{2}$ ratio: the ratio of arterial oxygen partial pressure to fractional inspired oxygen, $\mathrm{FEV}_{1}$ : forced expiratory volume in 1 second, FVC: forced vital capacity, Transfusion: perioperative packed red blood cell transfusion. 
such as newly developed arrhythmia, congestive heart failure, upper gastrointestinal bleeding, wound infection, and prolonged hospital stay, were found to be associated with impaired $\mathrm{FEV}_{1}$ or FVC $(<70 \%)$ [13]. However, in a study in patients aged $>60$ years who underwent laparoscopic gastrectomy, it was concluded that preoperative spirometry findings do not predict postoperative pulmonary complications [14].

Normal aging causes $\mathrm{PaO}_{2}$ and functional residual capacity to decrease and closing volume to increase. In a cross-sectional population-based survey, the strongest predictors of low oxygen saturation $\left(\mathrm{SpO}_{2}<95 \%\right)$ at a single-point measurement in the general adult population were found to be low predicted $\mathrm{FEV}_{1}$ $(<50 \%)$ and a body mass index of $>35 \mathrm{~kg} / \mathrm{m}^{2}$; other predictors were male gender, an age $>65$ years, and smoking history [15]. In addition, Vold et al. [16] reported that low oxygen saturation was independently associated with all-cause mortality and lung disease-related mortality in an age- and sex-adjusted cohort study. But, when their analysis included predicted $\mathrm{FEV}_{1} \%$ values, the strength of the association with lung disease-related mortality diminished but still remained significant [16]. No previous study has sought to identify predictors of postoperative desaturation in the extremely old. However, when considering the fact that age-adjusted analysis revealed the $\mathrm{FEV}_{1} \%$ weakened the strength for predicting mortality [16], it would appear age-related changes in $\mathrm{FEV}_{1}$ as well as the value of $\mathrm{FEV}_{1} \%$ might be closely associated with mortality. Meanwhile, there was no correlation between the preoperative spirometry and early postoperative desaturation events, but there was a correlation with the preoperative $\mathrm{PaO}_{2} / \mathrm{FiO}_{2}$ ratio in the extreme older patients of this study. In a previous clinical study, the preoperative low $\mathrm{PaO}_{2} / \mathrm{FiO}_{2}$ ratio has been reported to significantly increase the postoperative complications [17].

General anesthesia tends to increase the rates of respiratory complications, such as airway hyperactivity, increased dead space volume, and changes in lung volume and dynamic parameters [18]. In a meta-analysis of 31 studies involving 3,231 patients who underwent hip fracture surgery, the incidence of deep vein thrombosis was significantly lower after regional than that after general anesthesia [19]. Thus, if regional anesthesia is possible, it may be preferred over general anesthesia in older individuals. In a comparison of pulmonary function changes in the young (20-59 years) and older (60-85 years) adults after spinal anesthesia, $\mathrm{FVC}, \mathrm{FEV}_{1}$, and $\mathrm{FEF}_{25-75}$ results were significantly reduced in the older but not in the younger adults [9]. However, unlike a previous study in which sensory block levels were $>$ T6 [9], our target block levels for femur neck fracture surgery were $<$ Th6, and thus, the effect of spinal anesthesia per se on pulmonary function may have been minimal in our study.

Although no correlation was observed between preoperative pulmonary function and postoperative desaturation events, these events are known to be related to more events of delirium and major morbidities, including death, pneumonia, pulmonary thromboembolism, and upper gastrointestinal bleeding, and more frequent ICU stays. Furthermore, in the present study, $61 \%(11 / 18)$ of major morbidities were due to pulmonary complications. It is no surprise that hypoxia is accompanied by a neurologic manifestation such as restlessness or confusion and that delirium is present in many patients with hypoxia [20]. As aging progresses, older individuals become more vulnerable to respiratory complications because basal proinflammatory cytokine levels increase, respiratory function decreases, and immune response is progressively blunted [21-24]. In a recent retrospective analysis involving 140 patients aged $\geq 80$ years who underwent emergency general surgery, ASA physical status was found be the most powerful independent predictor of postoperative in-hospital mortality, and chronologic age and numbers of comorbidities were not found to predict surgical outcomes [25]. In this previous study, the overall mortality rate was $14.7 \%$ and the proportion of subjects with an ASA physical status of 3 or 4 was $90 \%$ [25]. However, the proportion of subjects in the present study with an ASA physical status of $\geq 3$ was only $48 \%$ and we excluded patients without spirometric results due to a fragile medical condition or poor cooperation, and thus, our results cannot be applied generally to patients $\geq 80$ years.

The present study has some limitations that warrant consideration. First, it is inherently limited by its retrospective nature. We could not find any conditions that might affect postoperative respiratory function, such as postoperative opioid consumption and a history of smoking or sleep apnea. In particular, the orders for rescue analgesics were usually conducted in pro re nata order, and hence, we could not confirm the actual use of analgesics. Second, we defined postoperative desaturation events using only $\mathrm{SpO}_{2}$ that may have underestimated the occurrence of desaturation as pulse oximeters that can easily slip off fingers may not give accurate measurements. In addition, it might be difficult to define postoperative hypoxia only with pulse oximetry in older individuals who are vulnerable to poor peripheral blood circulation. Also, pulse oximetry might be inadequate for the diagnosis of hypoxia because there are many factors that may cause measurement errors, such as hypotension, hypothermia, and the use of vasopressors. Some clinical reports defined postoperative hypoxia as $\mathrm{PaO}_{2} / \mathrm{FiO}_{2}$ ratio $<200$ [26], but we have defined desaturation as a reduction of the $\mathrm{SpO}_{2}$ instead of the $\mathrm{PaO}_{2} / \mathrm{FiO}_{2}$ ratio. A previous report has defined postoperative hypoxia as $\mathrm{SpO}_{2}$ of $<90 \%$ [11]. Third, we analyzed medical records of patients who underwent spinal anesthesia and excluded patients with contraindications to neuro-axial anesthesia, such as bleeding diathesis or lack of cooperation, and exclusion of these patients with a severe underlying disorder may have influenced our results. Finally, Nagelkerke $r^{2}$, a goodness-of-fit mea- 
sure for linear regression models, was only 0.08 in this study. This low value indicates that the percentage of the variances in the dependent variable that the independent variables explain collectively is low, and hence, a further large cohort study might be required to generalize our results.

In conclusion, preoperative $\mathrm{PaO}_{2} / \mathrm{FiO}_{2}$ ratio, but not preoperative spirometry, was predictive of the postoperative desaturation in older patients who were administered spinal anesthesia for femur fracture surgery. Based on our results, preoperative ABGA may be helpful in predicting early postoperative desaturation in such patients. Because postoperative desaturation is positively associated with morbidity, careful monitoring and appropriate management to prevent desaturation is essential in extreme older individuals.

\section{Conflicts of Interest}

No potential conflict of interest relevant to this article was reported.

\section{Author Contributions}

Youn Yi Jo (Conceptualization; Writing-original draft)

Chun Gon Park (Data curation; Formal analysis)

Ji Yeon Lee (Data curation)

Sun Koo Kwon (Data curation)

Hyun-Jeong Kwak (Conceptualization; Writing-review \& editing)

\section{ORCID}

Youn Yi Jo, https://orcid.org/0000-0002-9214-7039

Chun Gon Park, https://orcid.org/0000-0002-8269-5058

Ji Yeon Lee, https://orcid.org/0000-0003-0327-371X

Sun Koo Kwon, https://orcid.org/0000-0002-1901-5689

Hyun Jeong Kwak, https://orcid.org/0000-0003-4432-8510

\section{References}

1. Vaz Fragoso CA, Enright PL, McAvay G, Van Ness PH, Gill TM. Frailty and respiratory impairment in older persons. Am J Med 2012; 125: 79-86.

2. Sharma G, Goodwin J. Effect of aging on respiratory system physiology and immunology. Clin Interv Aging 2006; 1: 253-60.

3. Mannino DM, Davis KJ. Lung function decline and outcomes in an elderly population. Thorax 2006; 61: 472-7.

4. Susarla A, Kubiak EN, Egol KA, Karp A, Zuckerman JD, Koval KJ. Predictive value of preoperative arterial blood gas evaluation for geriatric patients with hip fractures. Am J Orthop (Belle Mead NJ) 2006; 35: 74-8.

5. Dayama A, Olorunfemi O, Greenbaum S, Stone ME Jr, McNelis J. Impact of frailty on outcomes in geriatric femoral neck fracture management: an analysis of national surgical quality improvement program dataset. Int J Surg 2016; 28: 185-90.

6. Clayer M, Bruckner J. Occult hypoxia after femoral neck fracture and elective hip surgery. Clin Orthop Relat Res 2000; (370): 265-71.

7. Brox WT, Chan PH, Cafri G, Inacio MC. Similar mortality with general or regional anesthesia in elderly hip fracture patients. Acta Orthop 2016; 87: 152-7.

8. Patorno E, Neuman MD, Schneeweiss S, Mogun H, Bateman BT. Comparative safety of anesthetic type for hip fracture surgery in adults: retrospective cohort study. BMJ 2014; 348: g4022.

9. von Ungern-Sternberg BS, Regli A, Reber A, Schneider MC. Comparison of perioperative spirometric data following spinal or general anaesthesia in normal-weight and overweight gynaecological patients. Acta Anaesthesiol Scand 2005; 49: 940-8.

10. Oğurlu M, Sen S, Polatli M, Sirthan E, Gürsoy F, Cildağ O. The effect of spinal anesthesia on pulmonary function tests in old patients. Tuberk Toraks 2007; 55: 64-70.

11. Maity A, Saha D, Swaika S, Maulik SG, Choudhury B, Sutradhar M. Detection of hypoxia in the early postoperative period. Anesth Essays Res 2012; 6: 34-7.

12. Kispert JF, Kazmers A, Roitman L. Preoperative spirometry predicts perioperative pulmonary complications after major vascular surgery. Am Surg 1992; 58: 491-5.

13. Phunmanee A, Tuntisirin C, Zaeoue U. Preoperative spirometry to predict postoperative complications in thoracic surgery patients. J Med Assoc Thai 2000; 83: 1253-9.

14. Huh J, Sohn TS, Kim JK, Yoo YK, Kim DK. Is routine preoperative spirometry necessary in elderly patients undergoing laparoscopy-assisted gastrectomy? J Int Med Res 2013; 41: 1301-9.

15. Vold ML, Aasebø U, Hjalmarsen A, Melbye H. Predictors of oxygen saturation $\leq 95 \%$ in a cross-sectional population based survey. Respir Med 2012; 106: 1551-8.

16. Vold ML, Aasebø U, Wilsgaard T, Melbye H. Low oxygen saturation and mortality in an adult cohort: the Tromsø study. BMC Pulm Med 2015; 15: 9 .

17. Lee JM, Kim HC, Park IJ, Kim DD, Yu CS, Kim JC. The characteristics of colorectal cancer in patients older than 80 years. J Korean Soc Coloproctol 2007; 23: 490-6. 
18. Saraswat V. Effects of anaesthesia techniques and drugs on pulmonary function. Indian J Anaesth 2015; 59: 557-64.

19. Guay J, Parker MJ, Gajendragadkar PR, Kopp S. Anaesthesia for hip fracture surgery in adults. Cochrane Database Syst Rev 2016; 2: CD000521.

20. Gossman W, Alghoula F, Berim I. Anoxia (hypoxic hypoxia). StatPearls [Internet]. Treasure Island (FL): StatPearls Publishing LLC; 2019 Jul [cited 2019 May 19]. Available from https://www.ncbi.nlm.nih.gov/books/NBK482316/

21. Boe DM, Boule LA, Kovacs EJ. Innate immune responses in the ageing lung. Clin Exp Immunol 2017; 187: 16-25.

22. Lowery EM, Brubaker AL, Kuhlmann E, Kovacs EJ. The aging lung. Clin Interv Aging 2013; 8: 1489-96.

23. Boyd AR, Orihuela CJ. Dysregulated inflammation as a risk factor for pneumonia in the elderly. Aging Dis 2011; 2: 487-500.

24. United Nations. World Population Ageing Report 2015 [Internet]. New York: United Nations; 2015 [cited 2019 May 19]. Available from https://www.un.org/en/development/desa/population/publications/pdf/ageing/WPA2015_Report.pdf

25. Merani S, Payne J, Padwal RS, Hudson D, Widder SL, Khadaroo RG. Predictors of in-hospital mortality and complications in very elderly patients undergoing emergency surgery. World J Emerg Surg 2014; 9: 43.

26. Ranucci M, Ballotta A, La Rovere MT, Castelvecchio S. Postoperative hypoxia and length of intensive care unit stay after cardiac surgery: the underweight paradox? PLoS One 2014; 9: e93992. 